\title{
LOCATING STATIONS OF PUBLIC TRANSPORTATION VEHICLES FOR IMPROVING TRANSIT ACCESSIBILITY
}

\author{
Hassan Ziari', Mahmud R. Keymanesh ${ }^{2}$, Mohammad M. Khabiri ${ }^{3}$ \\ ${ }^{1}$ Dept of Civil Engineering, Iran Science and Technology University, Iran \\ E-mails: ${ }^{1}$ H.Ziari@iust.ac.ir; ${ }^{2}$ Mrkeymanesh@wanadoo.fr; ${ }^{3}$ Khabiri@iust.ac.ir
}

Received 27 September 2006; accepted 12 December 2006

\begin{abstract}
Since transportation is one of the most complicated and the basic problem of urban life in developing countries at the present time and in various dimensions, so it is necessary to view it more scientifically- practically.

Reducing travelling time is one way to reduce its cost .In public transportation system, it is important to determine proper travelling costs. There are various methods to determine the distances between stations. One of these methods used in England is based on logical and calculative relations in mathematics. In this paper, in addition to studying this method some changes have been made in order to reduce and modify required variables for calculation of those relations. A numerical example is designed to demonstrate the effectiveness of the method and thus developed to optimize the public transportation stop location problem. The sensitivity of the total travel time, access, speed and the effect of the parameters on the optimum stop location are analyzed and discussed.
\end{abstract}

Keywords: bus stops planning, access distance, optimization, travel time, locating, public transportation.

\section{Introduction}

We pay attention to the expansion of using public transportation in order to develop the social justice. The facilities prepared by public expenses to expand the society welfare, should be based on the planning and scientific viewpoints. There are a lot of factors which have an effect on determining the route of mass transportation vehicles, for example the terminals, kind of vehicles, (as per capacity, speed, and technical quality) and the kind of route lines network (radical, chessshaped, diametrical networks, etc).

In Iran, the urban buses are used as a public transportation (now, other public transportation systems, such as subway, are used in some special routes). This is a subject that can be used for various systems of public transportation, (bus, subway, tramway, etc.) in which the persons walk from the origin-origin station to destination, station-destination. By expanding this subject, the obtained results, also, can be used for the persons who move from the origin - origin station to destination station-destination by bicycle, car or local bus.

In this paper, a mathematical model is formulated to optimize the locations of bus stops that achieve the minimum total travel time.

\section{Literature review}

The method applied for analyzing the transit system performance was based on the relationship between stop spacing service, headway ,fleet size and round trip travel time. The objectives of those studies were using these relationships to evaluate system capacity versus actual demand and required headway versus policy headway to minimize the total cost (the sum of supplier and user costs). It was believed that the performance of a transit system could be significantly improved if the spacing of bus stops was optimized. The review of past research for this study on optimizing location of bus stops can be classified into three categories. The first involved studies that focused on locating bus stops based on simplified demand distribution. A review on bus stops plan was conducted by Fitzpatrick et al. [1] who developed strategy for allocating bus stops considering bus patron's convenience, safety and access time, as well as the efficiency of transit operations. Based on given traveller preferences and funds constraints from the transit provider, Van Nes and Bovey [2] developed a logical model that optimized stop spacing and line spacing, while a number of performance indices (i.e. travel time, operator costs, and patronage) were analyzed. Due to the fact that buses compete for the right of way with other transportation modes, Brouwer [3] and Wirasinghe and Ghoneim [4] optimized the locations of bus stops in view of the costs incurred not only by bus passengers and transit suppliers, but also by other road users, local residents and businesses.

The second group focused on joint optimization of bus route and stop spacing for a bus system. Holroyd [5] analyzed a grid bus net with a given origin- 
destination (O-D) demand that was uniformly distributed over an infinite plane. The route spacing and headway were optimized, which achieved the minimum total cost. Later Chien and Schonfeld [6] optimized a grid transit system in a heterogeneous urban area without oversimplifying the spatial and demand characteristics. An iterative algorithm was developed to minimize the total cost, while the bus route spacing, stop spacing and headways were optimized. Chien et al. [7, 8] found the best number and locations of bus routes serving a CBD and a residential area by minimizing the total cost using genetic algorithms. Since passengers were assumed to be able to access buses anywhere on the route (e.g. jitney service), the locations of the bus stops were not measured.

In the third group, several studies have considered temporal demand while optimizing a bus system. Gerard and Hundle [9] optimized a service area by minimizing the total cost considering time varying demand. Bramel and Simchi-Levi [10] applied heuristic methods to answer a vehicle routing problem in which customers requested service with an assured probability during a given time period. Most of the aforementioned studies considered additive time cost while optimizing their objective functions.

\section{Establishment place of bus stations}

We determine the place of bus stations mainly as per distance between stations. The suitable place for bus stations should be determined as per model of the passersby movement and the establishment position of the traffic production centre.

The travel time from the beginning to the ending place is as follows.

1. Walking time up to the public transportation vehicle station (origin-origin station).

2. Walking time to public transportation vehicle.

3. Time of getting on the public transportation vehicle.

4. Reputation time of an alternative movement of a vehicle for arriving to the next station consists of:

4.1. enough time for the vehicle to develop the acceleration constant speed;

4.2. the time in which a vehicle moves between two stations;

4.3. enough time for a vehicle to get to the deceleration station.

5. Stopping time in the stations along the route.

6. Delay time and occasional delays.

7. Time of getting off the vehicle.

8. Time of walking to the destination or replacing transportation system, or changing the public transportation vehicle.

The purpose of this research is to study factors having an effect on minimizing the travel time, accessing to transport for the passengers and determining the delays. In this research, efficiency of the public transportation system is measured by the travel speed, and jour- ney speed, so that these parameters will be obtained as per travel time and journey time.

\section{Current methods of estimating the distances between the stations}

In designing the urban bus system, some points such as network design, travel allocation, determination of distances between stations, etc. will be considered. The distance between stations means the distance between two next stations, so that in designing the bus transportation network, the distance between the central stations means the bus line length. Now let us examine two alternative design methods.

\section{1 - Determination of the distances between stations as per density of the population}

According to the kind of use, land, and needs, the distance between the stations is determined for the city centre, as per change of the population density in different zones of the city. the following values are suggested for the distances between the stations:

1. The distance between stations in the city trade center, is determined from 750 to $250 \mathrm{~m}$ with population density of more than 3500 persons in every $\mathrm{km}^{2}$.

2. The distance between stations in the city center, with an average density from 1000 to 3500 persons in every $\mathrm{km}^{2}$, is determined from 200 to $300 \mathrm{~m}$.

3. The distance between stations, in the suburb of city, with an average density of less than 1000 persons, in every $\mathrm{km}^{2}$, is determined from 250 to $3000 \mathrm{~m}$.

\section{2 - Determination of the distance between stations by the popular method in England}

This method is recognized as an acceptable one and it is presented as per the time of optimal covering the distance between stations.

The method uses some variables of the travel time, such as average speed, travel length, and firstly of the public transportation properties and characters. Ten factors affecting the calculations are as follows:

- The average distance covered by every travel (m): $L$.

- The average distance between the stations (m): $D$.

- The average distances that vehicle increases or decreases its speed (m): $A$.

- Performing time of process (s): $B$.

- Constant speed of passengers' movement (m/s): $F$.

- Constant speed of a vehicle in the distance between the stations $(\mathrm{m} / \mathrm{s}): V$.

- Average distance for getting to destination or origin is almost equal (m): $X$.

- Stopping time in every station (s): $S$.

- Travel time is (s): $T$.

Travel time is obtained by collection of the above mentioned times. The relations (1) and (2) show how to calculate the time. 


$$
T=2 \cdot \frac{X}{F}+\frac{L}{D} \cdot S+\frac{L}{D} \cdot B+\frac{L}{D} \cdot \frac{(D-A)}{V}
$$

or

$T=$ (travel time for getting to the first station) $\times 2+$ (quantity of stations $\times$ stopping time in every station $)+($ quantity of movements at stations $\times$ time of constant speed of movement) + (quantity of movements at stations $\times$ acceleration and deceleration time).

The most desirable services of the vehicles are necessary to be served as soon as possible so the relation (2) as per $D$ (the distance between stations) will be changed into unknown for minimizing travel time $T$. We take a function from relation (2) as per $D$ and it is considered as a zero value, and $D$ is solved as the only unknown:

$$
\frac{d T}{d D}=0 \text {. }
$$

The values of variables $L, A, B, V, F, S, X$ are determined in statistical ways. For example, Table shows the variables which are determined for public transportation system.

$$
\begin{aligned}
& T=\left(\frac{D}{4} \cdot 2\right)+\left(\frac{5000}{D} \cdot 20\right)+\left(\frac{5000}{D} \cdot 204\right)+ \\
& \left(\frac{5000 \cdot(D-144)}{D \cdot 12}\right), \\
& T=1020000 \cdot D^{-1}+0.5 \cdot D+417 .
\end{aligned}
$$

For minimizing the travel time, we take a function from relation (5), the function is considered as a zero:

$$
\begin{aligned}
& \frac{d T}{d D}=-1020000 \cdot D^{-2}+0.5 \\
& 0=-1020000 \cdot D^{-2}+0.5 .
\end{aligned}
$$

Variables for public transportation system

\begin{tabular}{|c|c|}
\hline Variable & Value \\
\hline$L$ & $5 \mathrm{~km}$ \\
\hline$A$ & $144 \mathrm{~m}$ \\
\hline$B$ & $204 \mathrm{~s}$ \\
\hline$V$ & $43 \mathrm{~km} / \mathrm{h}$ \\
\hline$F$ & $3.6 \mathrm{~km} / \mathrm{h}$ \\
\hline$X$ & $0.25 D \mathrm{~m}$ \\
\hline$S$ & $12 \mathrm{~s}$ \\
\hline$D$ & $? m$ (need to determine) \\
\hline$T$ & $?$ s (need to determine) \\
\hline
\end{tabular}

In addition, $D$ value is obtained by relation (7), i.e. $1428 \mathrm{~m}$. Thus the suitable distance between stations is $1428 \mathrm{~m}$ for this system. By drawing function $t$ as per $D$, Fig 1 is provided.

\section{Accessing to public transportation system}

For accessing to public transportation, one of the most usual methods is a walking one. It means the distance access in which a person covers the distance from the origin toward the station to get to the destination. This distance is considered about $500 \mathrm{~m}$ for the local buses (the passengers, normally and safely, cover this route in five minutes and the disabled people in wheel chairs and the old need two times more than the above mentioned time).

Consequently, $95 \%$ of persons will be able to walk to the first station, $88 \%$ of passengers cover this distance in about $6 \mathrm{~min}$, and $12 \%$ of passengers cover this distance in 7 or $12 \mathrm{~min}$, because there are some obstacles for covering the distance in the zone or there are some movement disabilities of the person. That is normal probability curve combing drowning for this purpose. Fig 2 shows the possibility of the passengers for walking to the station.

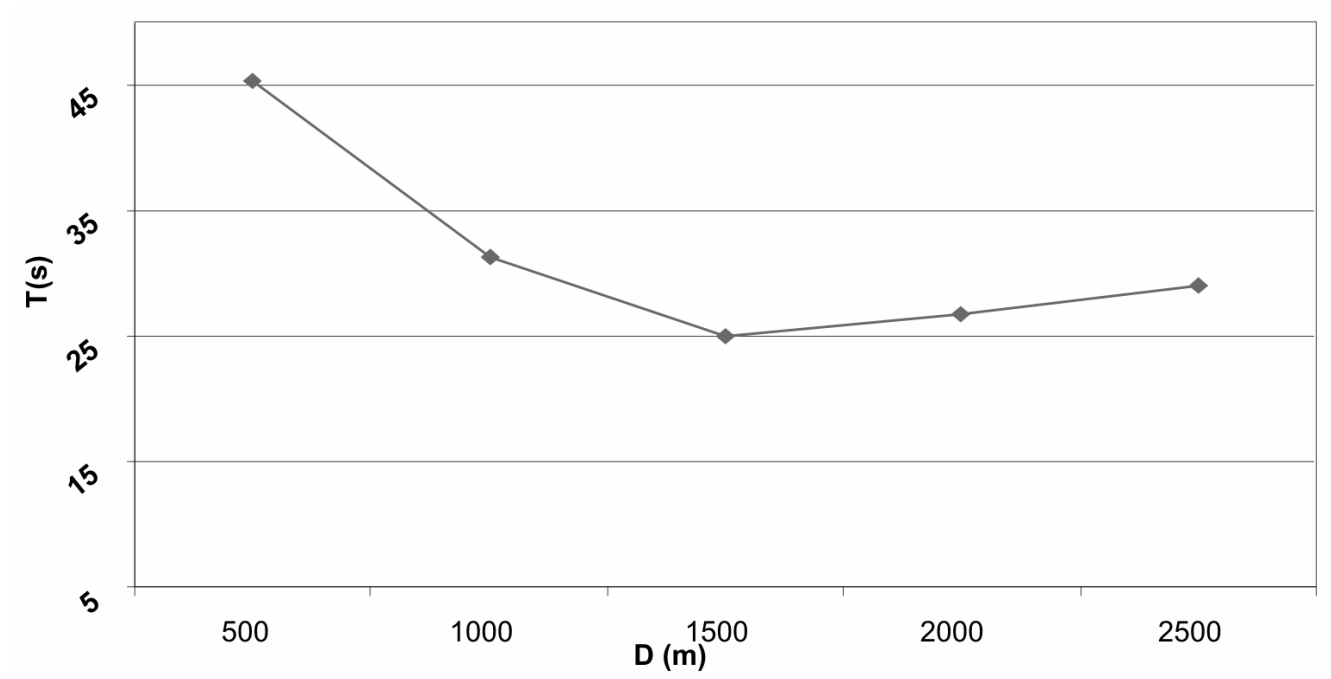

Fig 1. Relation between travel time and station distance 


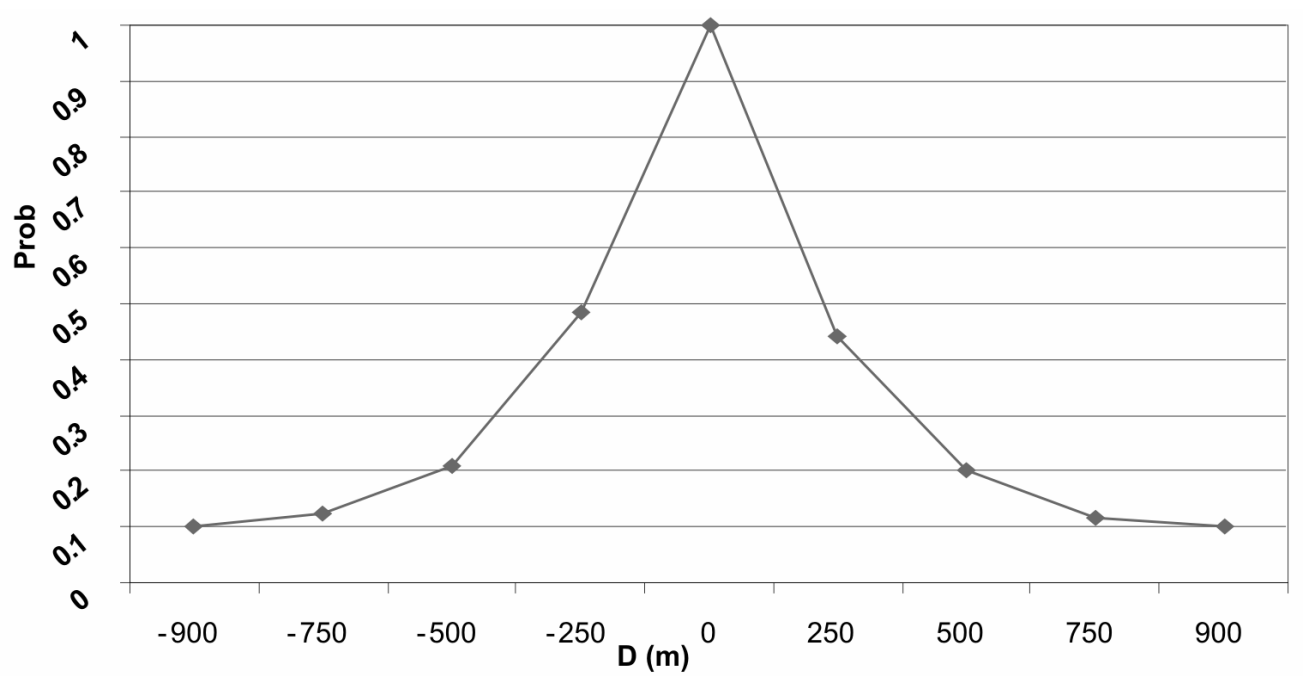

Fig 2. A probability graph for walking to origin station

Of course, this value is used in normal conditions. If we are in peak house of traffic and passengers, this distance is tolerable and better.

\section{Calculating the distance access}

Firstly access to transportation engineering was based on measuring the intercity distance so that this distance may be ground or air distance or time factor [11-13]. A more comprehensive index of accessibility suggested by W. Hansen is described in the from of the population relation to the distance. Then $T$. Matis expanded this concept.

Detailed access capabilities (social, trade and occupational) of the zone were given in calculating the distance access. In calculation of access, distance is given to the bus station by Hansen's method as per ground distance in relation (8):

$$
d=\frac{\sum_{i=1}^{n} P_{i}^{2} \cdot d_{i}}{\sum_{i=1}^{n} p_{i}^{2}},
$$

where: $P_{i}$ - population in the scope of the zone (person); $d_{i}-$ distance of scope from the station (m); $h-$ quantity of scopes in the zone; $p$ - zone population (person); $d$-access distance to the station (m).

$$
P_{i}=A_{i} \cdot S,
$$

where: $A_{i}$ - scope level from the zone $\left(\mathrm{m}^{2}\right) ; S$ - average density of zone (person $/ \mathrm{m}^{2}$ ).

Actually, in relation (8) the distance access to the zone station, up to emphasizing the population has been obtained. Relation (8) is like weight calculation relation of numerical average. It is necessary to cover the distance between departure and vice versa, to get public transportation status.

Passenger traffic is the less this time, more effective in attraction of public transportation, and travel time will be reduced. Travel time speeded by passenger in covering the departure-destination is, as follows:

- the time in which the passenger uses public transportation vehicle;

- the time in which the passenger is waiting for the vehicle.

If the distance between the stations increases, the access distance will be increased. The increase specifies the access distances.

In the form of linear function from the distance between stations, the coefficient of the access distance $(d)$ to the relation of the distance between station $(D)$ and coefficients $a$ and $b$ are calculated according to linear regression as per statistical data:

$$
d \propto D
$$

$$
D=a \cdot d+b .
$$

As per zones with the different uses and (3) the passengers' speed $V_{i}$ will be constant when covering the distance from the origin-station of origin, to destination station-destination, so the constant time of the travel $T_{i}$ is determined:

$$
\begin{aligned}
& T_{i}=\frac{D_{i}}{V_{i}}, \\
& T_{i}=\frac{a \cdot d+b}{V_{i}} .
\end{aligned}
$$

Moving time of vehicle between stations consists of the time between stopping point and constant speed. Moving time with constant speed and arrival time from the constant speed to stopping position are given in relation:

$$
T_{i}=\frac{D}{V_{2}}+C
$$


where: $D$ - the distances between stations; $V_{2}-$ constant average speed of the vehicle (constant average speed after increasing acceleration and before reducing acceleration); $C$ - average time from stop situation to constant speed or average time from constant speed to stopping situation $(B=C+S) ; S$ - average waiting time in the station which is constant time.

Travel time described equals to a collection of 3 times, if the length of vehicle route is $L$ and the distance between the stations is $D$, the quantity of necessary stations will be $\frac{L}{D}$ for the route and travel time is obtained by relation (15):

$$
T=\left(\frac{D}{V_{2}}+C+S\right) \cdot \frac{L}{D}+2 \cdot\left(\frac{a \cdot d+b}{V_{1}}\right) .
$$

And according to the previous case, by getting the function from relation (15) as per $D$ and considering it as zero and simplifying it, relation (16) will be obtained:

$$
D=\left(\frac{(C+S) \cdot L \cdot V_{1}}{2 \cdot a}\right)^{\frac{1}{2}} .
$$

If we use the variables $V_{1}=1, S=12, C=192$, $L=5000, a=0.25$ of the previous public transportation, the distance between stations, i.e. $1428 \mathrm{~m}$ will be obtained.

\section{Discussion results}

One of the consequences of simplifying this relation is reducing the parameters which are obtained statistically, the measurements are the other consequences that can be performed more logically (for example, variable a, as per meter, was omitted):
1. The method of calculating access time to origin station or moving from destination station to destination has a mere logical than calculation form.

2. Travel time can also be calculated by relation (17):

$$
T=\left(\frac{D}{V_{2}}+C+S\right) \cdot \frac{L}{D}+2 \cdot\left(\frac{a \cdot d+b}{V_{1}}\right)
$$

We suggested the following way to reduce the distance between stations without increasing travel time:

3. Acceleration or the rate of changing the vehicle speed can be increased by the new systems.

4. By increasing the facilities inside the station for getting off and increasing the passengers' information the stopping time will be decreased in the station.

5. To continue the research, some factors can be defined for one of the components of time, which are used by the passengers. Travel time can be defined as per priority of time for the passengers.

6. This research can be continued for different modes of access (for example, bicycles, local buses, etc.).

The sensitivity analysis is conducted to show the relationship between various parameters and design variables. The value of each parameter is changed based on their base line values, and new optimal decision variables are computed. The results are shown in Fig 3.

The development of an analytical approach in this study has been demonstrated while the relationship between parameters (e.g. access speed) and variables (locations of bus stops) has been derived. The model as developed can be applied to determine the optimal locations of bus stops considering realistic street patterns and demand distributions. It is found that the optimal solution to locations of the stops will be affected by access speed and access distance.

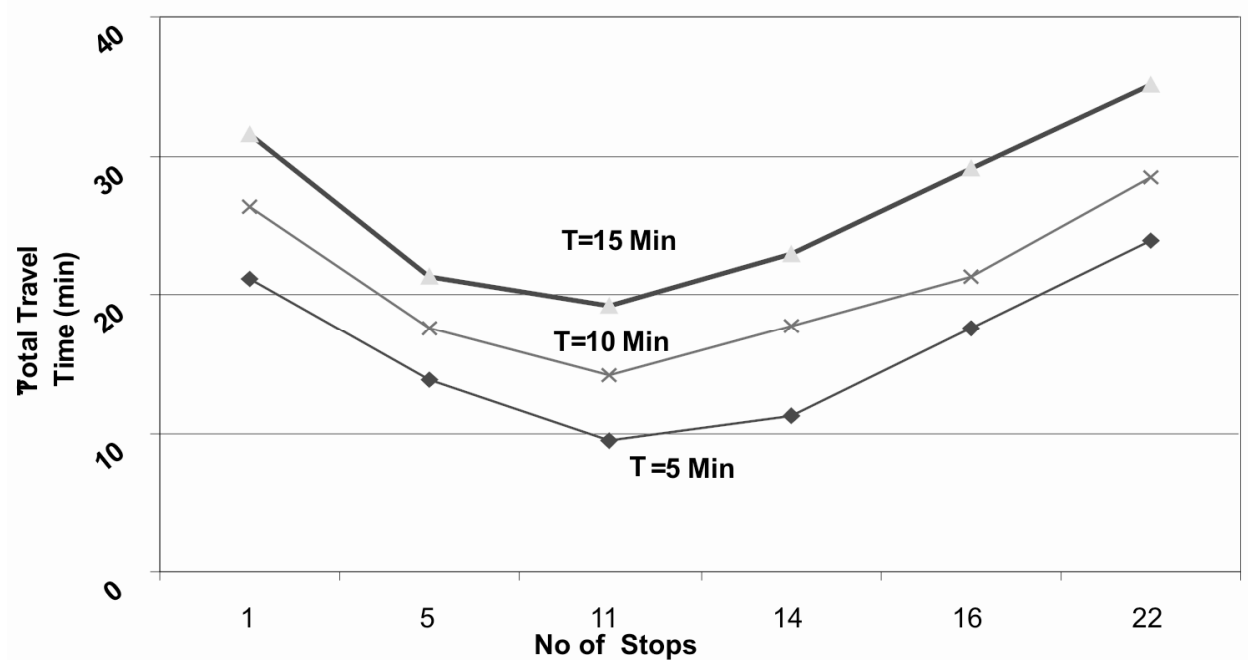

Fig 3. Total travel time plotted for a number of stops for various users of vehicle time 


\section{References}

1. FITZPATRICK, K.; PERKINSON, D.; HALL, K. Findings from a survey on bus stop design. Journal of Public Transportation, 1997, 1 (3), p. 17-27.

2. VAN NES, R.; BOVEY, P. H. L. Importance of objectives in urban transit-network design. Transportation Research Record, 2000, 1735, p. 25-34.

3. BROUWER, P. Position and design of bus stops in urban areas. UITP Revue, 1983, 32(1), p. 74-76.

4. WIRASINGHE, S. C.; GHONEIM, N. S. A. Spacing of bus-stops for many-to-many travel demand. Transportation Research Record, 1981, 15 (3), p. 210-221.

5. HOLROYD, E. The optimal bus service: a theatrical model for a large uniform urban area in vehicular traffic science. Elsevier, New York, 1967.

6. CHIEN, S.; SCHONFELD, P. Optimization of grid transit system in heterogeneous urban environment. Journal of Transportation Engineering, 1997, 123(1), p. 28-35.

7. CHIEN, S.; YANG, Z. Optimal feeder bus routes with irregular street networks. Journal of Advanced Transportation, 2000, 34 (2), p. 213-248.

8. CHIEN, S.; YANG, Z.; HOU, E. A genetic algorithm approach for transit route planning and design. Journal of Transportation Engineering, 2000, 127(3), p. 200-207.

9. GERRAND, C.; HUNDLE, V. F. An operating strategy for a commuter bus system. Transportation Science, 1975, 9(1), p. 1-20.

10. BRAMEL, J.; SIMCHI-LEVI, D. Probabilistic analysis and practical algorithms for the vehicle routing problem with time windows. Operations Research, 1996, 44(4), p. 501-559.

11. WHITE, P. Public transport and management and operation London. Prentice Hall, PP 230, 1995.

12. BEHBAHANI, H.; SHAHI, J. Congestion of travel demand. Yazd University, 1996.

13. BEHBAHANI, H.; KHABIRI, M. M. Locating stations of public transportation vehicles according to distances between stations on the basic of calculative relation, Journal of Iranian Society of Engineers, 2001, Vol 4, No 12. 